\title{
Global patterns of rainfall partitioning by invasive woody plants
}

\author{
Juan I. Whitworth-Hulse ${ }^{1,2}$ (D) | Patricio N. Magliano ${ }^{1,3}$ | Sebastián R. Zeballos ${ }^{2}$ | \\ Sebastián Aguiar ${ }^{4}$ | Germán Baldi ${ }^{1}$
}

${ }^{1}$ Grupo de Estudios Ambientales - IMASL, Universidad Nacional de San Luis \&

CONICET, San Luis, Argentina

${ }^{2}$ Instituto Multidisciplinario de Biología Vegetal (IMBIV), Universidad Nacional de Córdoba \& CONICET, Córdoba, Argentina

${ }^{3}$ Departamento de Bioquímica y Ciencias Biológicas, Facultad de Química, Bioquímica y Farmacia, Universidad Nacional de San Luis, San Luis, Argentina

${ }^{4}$ Instituto de Investigaciones Fisiológicas y Ecológicas Vinculadas a la Agricultura (IFEVA), Facultad de Agronomía, Universidad de Buenos Aires, CONICET, Buenos Aires, Argentina

\section{Correspondence}

Juan I. Whitworth-Hulse, Grupo de

Estudios Ambientales - IMASL, Universidad Nacional de San Luis \& CONICET, Ejército de los Andes 950, D5700HHW, San Luis, Argentina.

Email: jiwhulse@gmail.com

Funding information

Agencia Nacional de Promoción Científica y Tecnológica, Grant/Award Number: PICT 2016-4136

Editor: Zhiheng Wang

\begin{abstract}
Aim: Invasive species have the potential to alter hydrological processes by changing the local water balance. However, general patterns of how rainfall is partitioned into interception, throughfall and stemflow for invasive species worldwide have been seldom explored. We (a) describe the percentage of interception, throughfall and stemflow for invasive woody plant species; (b) analyse the influence of morphological attributes (i.e. life-form, bark roughness, leaf type, leaf phenology and leaf area index) of invasive species on rainfall partitioning; and (c) compare the rainfall partitioning fluxes for co-occurring invasive and native species, testing whether the variation in these fluxes depends on water availability of the study location.
\end{abstract}

Location: Global.

Time period: Present.

Major taxa studied: Plants.

Methods: We compiled data of 100 studies that assessed rainfall partitioning by invasive species $(n=67)$ and registered their morphological attributes. By means of a meta-analysis we compared the rainfall partitioning by native and invasive species ( $n=47$ comparisons) and assessed how their fluxes were affected by water availability.

Results: Interception, throughfall and stemflow ranged from 1.6-59.5, 39.1-92.7 and $0.1-31.6 \%$ of total rainfall, respectively. The bark roughness and leaf type were the most important attributes driving rainfall partitioning fluxes. While rough-barked species constrain rainfall inputs by promoting higher losses due to interception, smooth-barked species with broad leaves enhance the amount of rainwater reaching the soil by maximizing stemflow. For pairwise comparisons, invasive species have higher stemflow values than native species for both drylands and humid areas, and higher throughfall in drylands, but less in humid areas.

Main conclusions: Our findings suggest that specific morphological attributes of invasive species determine higher localized water inputs, which may represent an ecohydrological advantage, particularly in water-limited ecosystems. These insights also suggest that the ecological role of stemflow, throughfall and interception should be considered in future plant invasions research.

KEYWORDS

aridity, biological invasion, ecohydrology, meta-analysis, stemflow, woody plants 


\section{1 | INTRODUCTION}

Hundreds of woody plant species have been introduced out of their natural distribution ranges for multiple purposes, such as forestry, food and ornamental uses; and a group of them have become invasive, altering ecosystem stability and functioning (Ehrenfeld, 2010; Richardson \& Rejmánek, 2011; Vilà \& Hulme, 2017). A myriad of studies have described how morphological and functional attributes are related to plant invasions (Gross et al., 2013; Nunez-Mir et al., 2019; Van Kleunen et al., 2010), but fewer have assessed their ability to distribute rainwater in the ecosystem in general and towards the root zone in particular (Cavaleri \& Sack, 2010; Sadeghi et al., 2017). Recent studies highlight that invasive plants can change the liquid and gaseous fluxes of the water balance (e.g. rainfall partitioning and evapotranspiration) at both patch and catchment level (Le Maitre et al., 2015; Vilà \& Hulme, 2017; Whitworth-Hulse et al., 2020). However, these studies rarely compare the rainfall partitioning (i.e. interception, throughfall and stemflow) within invasive species and between native and invasive species co-occurring in the same environment. Hence, a comparative assessment of their rainfall partitioning might shed light on the ecohydrological processes underlying plant invasions.

In woody-dominated ecosystems, rainfall partitioning into interception, throughfall and stemflow determines the amount and spatial distribution of rainwater entering into the soil (Figure 1a; Llorens \& Domingo, 2007; Magliano, Whitworth-Hulse, \& Baldi, 2019; Van Stan et al., 2020). Interception is the fraction of incident rainfall (11-45\% of the total; Magliano, Whitworth-Hulse, \& Baldi, 2019) retained by the canopy and lost during and after rainfall events via direct evaporation (Coenders-Gerrits et al., 2020). Throughfall is the fraction (31-88\% of total rainfall, Magliano, Whitworth-Hulse, $\&$ Baldi, 2019) that reaches the top soil directly through the canopy gaps without touching the canopy or via dripping from leaves and branches (Sadeghi et al., 2020). By funnelling rainwater down the (a)

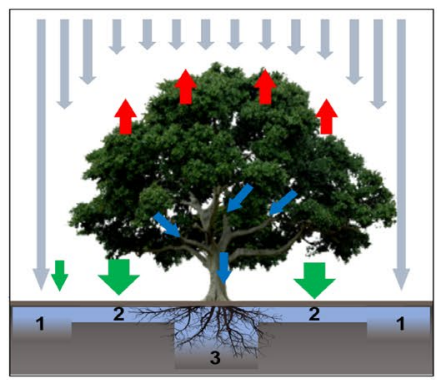



(d) (c)

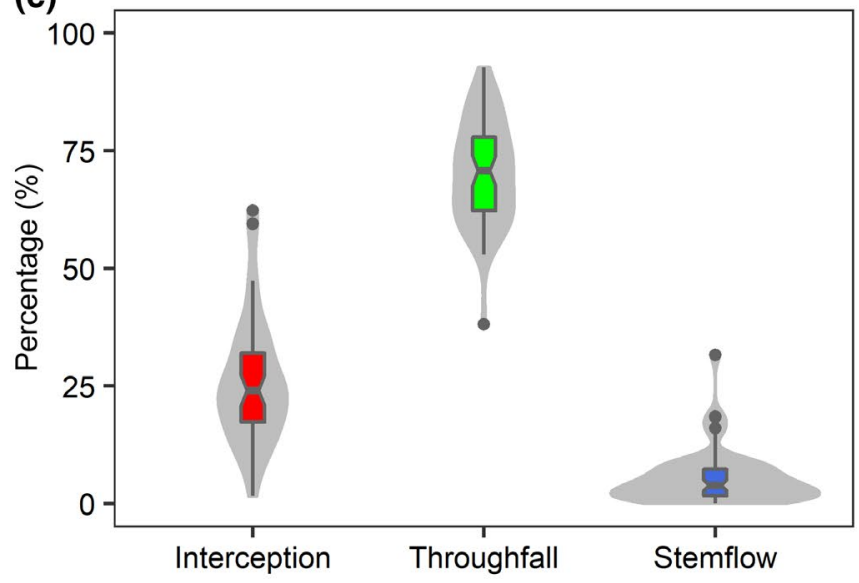



FIGURE 1 Conceptual diagram of rainfall partitioning for an individual tree in a woody plant dominated ecosystem (a). Grey arrows indicate rainfall, which can be partitioned into interception (red arrows), throughfall (green arrows) and stemflow (blue arrows). The numbered rectangles in the soil profile represent the three hypothetical zones of rainwater input (infiltration): directly from rainfall (1), from throughfall (1 and 2), and from stemflow (3). The geographic location of the 100 studies included in the analysis (b). The stars represent studies related to invasion ecology and circles other disciplines. Violin plots of rainfall partitioning into the percentage of interception, throughfall and stemflow for all invasive woody plant species (c) and for the invasive species (top 10) with a wide invaded distribution range (d). The width of each violin reflects the data density and the crossbar within the box indicates the median; the length of the box reflects the interquartile range; and the whiskers show the $95 \%$ confidence interval. Dots represent the outliers of the fluxes 
trunk, stemflow is the fraction of incident rainfall $(0.3-43 \%$ of the total, Magliano, Whitworth-Hulse, \& Baldi, 2019) that represents a localized water input, reaching deeper soil layers and becoming available for the roots (Levia \& Germer, 2015; Sadeghi et al., 2020).

Rainfall partitioning is determined by the interaction of multiple morphological attributes of woody species (Van Stan et al., 2020). Previous reviews highlighted that attributes related to plants' structure and architecture such as life-form, canopy size, branch architecture, leaf phenology, and leaf and bark morphology play an important role regulating rainfall partitioning fluxes (Barbier et al., 2009; Llorens \& Domingo, 2007; Magliano, Whitworth-Hulse, $\&$ Baldi, 2019). While evergreen and dense canopies favour interception (Carlyle-Moses \& Gash, 2011; Van Stan et al., 2020), open canopies with smooth barks and steeply inclined branches promote throughfall and stemflow (Magliano, Whitworth-Hulse, Florio, et al., 2019; Park \& Cameron, 2008). Hence, the shape of the canopy provides a preliminary insight into how rainfall is partitioned. For example, inverted cone-shaped plants with a highly ramified canopy such as Larrea spp. show higher efficiency in funnelling down rainwater via stemflow in comparison with cone-shaped plants with horizontal branches such as Pinus spp. (Magliano, Whitworth-Hulse, \& Baldi, 2019).

In terms of water availability for plant consumption, interception represents a net loss, while throughfall and stemflow contribute to the spatial redistribution of rainfall, and, therefore, increase soil water resources and plant productivity (Li et al., 2008; Van Stan et al., 2020). These ecohydrological processes have been addressed in plantations and in many ecosystems worldwide dominated by native species (e.g. plantations in semiarid areas, Sadeghi et al., 2016; tropical forests, Park \& Cameron, 2008; Mediterranean forests and shrublands, Llorens \& Domingo, 2007). For instance, Magliano, Whitworth-Hulse, and Baldi (2019) found that interception decreases and stemflow increases, towards the drier areas across an aridity gradient, leading to higher water inputs. They attributed these findings to the higher abundance of shrubs (mainly smoothbarked species with inclined stems), which maximized stemflow generation in comparison with trees (rougher bark species) that were more abundant in the sub-humid edge of the gradient.

In the context of plant invasions, a few studies have assessed the rainfall partitioning by exotic species and its association with plant morphological characteristics (Sadeghi et al., 2017; Safeeq \& Fares, 2014; Takahashi et al., 2011; Whitworth-Hulse et al., 2020). Many invasive plants with dense canopies have the capacity to replace native forests and shrublands forming monodominant invaded patches (Richardson \& Rejmánek, 2011), which may enhance interception loss with negative effects on soil water availability (e.g. Hawaii tropical dry forests ecoregion; Takahashi et al., 2011). In the Central Persian desert basins ecoregion (Iran), Sadeghi et al. (2017) highlighted that stemflow generation could be a key process for explaining the invasion of the smooth-barked tree Ailanthus altissima Mill. (tree of heaven). This study hypothesized that the great amounts of localized input of water via stemflow can provide ecohydrological benefits contributing to the plant's invasion success in drylands, which could be particularly important for invasive species whose native distribution is more humid than their expanded distribution. However, to the best of our knowledge, there is no evidence of global studies focused on rainfall partitioning by invasive species and its comparison with native vegetation. Therefore, identifying the morphological attributes that maximize, reduce or do not affect rainwater inputs may contribute to improve the understanding of the ecohydrological processes in the invaded environments.

The objectives of this study were (a) to review the percentage of interception, throughfall and stemflow for the invasive woody plant species at a global level; (b) to analyse the influence of morphological attributes (i.e. life-form, bark roughness, leaf type, leaf phenology and leaf area index) of invasive species on rainfall partitioning fluxes for invasive woody species; and (c) to compare the rainfall partitioning fluxes for co-occurring invasive and native species, testing whether the variation in these fluxes depends on water availability (i.e. aridity index) of the study location. To address these issues, we conducted a literature review and built databases comprising invasive and native woody plant species, for which we characterized their rainfall partitioning fluxes, morphological characteristics and the aridity index of their location.

\section{2 | MATERIALS AND METHODS}

\section{1 | Literature review}

In order to accomplish the first objective, we carried out an exhaustive systematic literature review to generate a database regarding the rainfall partitioning for the 751 invasive woody plant species (434 trees and 317 shrubs) listed by Rejmánek and Richardson (2013). These authors define invasive species as those species that (a) have sustained self-replacing populations for at least 10 years without direct human intervention by recruitment from seed or ramets capable of independent growth; and species that (b) recruit the reproductive offspring at considerable distances from the parent plants and thus have the potential to spread over a large area. We performed the survey in Scopus and Google Scholar using the following keywords: 'the scientific names of each invasive species' OR 'woody' OR 'tree' OR 'shrub' OR 'invasive' AND 'species' AND 'rainfall' AND 'partitioning' OR 'interception' OR 'throughfall' OR 'stemflow'. We selected 100 studies published in peer reviewed journals encompassing multiple disciplines such as hydrology, meteorology, biogeochemical cycles, forestry, agroforestry and invasion ecology (Figure 1b; Supporting Information Appendix S1, Table S1.1). The database included 67 invasive woody plant species (61 trees, 6 shrubs) across all continents except Antarctica. For each study location and invasive species, we extracted the percentage of the total rainfall that is partitioned into interception, throughfall and stemflow (for details of each flux value, scale and length of experiment see Supporting Information Appendix S1, Table S1.1). The reviewed information showed that the plant genera most frequently studied were Pinus 
(19\%), Acacia (9\%), Eucalyptus (6\%), Picea (3\%) and Populus (3\%). Following the world region classification presented by Richardson and Rejmánek (2011), we found that almost $70 \%$ of the studies surveyed took place in Europe (38\%), North America (16\%) and Asia (14\%). Complementarily, we explored the invaded and native distribution ranges of the selected invasive species in terms of ecoregion (Olson et al., 2001) and aridity (see details in Supporting Information Appendix S1, Text S1.1, Tables S1.2 and S1.3).

In order to accomplish the second objective, we gathered information on morphological attributes of the invasive species under study from multiple data sources (see details in Supporting Information Appendix S1, Table S1.1). With respect to life-form (i.e. tree or shrub), we used the information provided by each selected study, and in the cases where information was not available, we followed the classification proposed by Rejmánek and Richardson (2013). These authors define trees as perennial woody plants attaining a height of at least $3 \mathrm{~m}$, with many secondary branches supported clear off the ground on a single main stem with apical dominance. Shrubs were classified as the woody plants that did not meet these criteria. Regarding other species characteristics, such as bark roughness (i.e. rough or smooth), leaf type (i.e. broadleaf, needle-leaf or pinnate-leaf), leaf phenology (i.e. evergreen or deciduous) and leaf area index (LAl, as a proxy of canopy density), we also used the information provided by the selected studies or from open access databases, including the Global Invasive Species Database (www.iucng isd.org/gisd/), the Useful Tropical Plants (tropical.theferns.info/), the Missouri Botanical Garden (www.missouribotanicalgarden.org) and the TRY Plant Trait Database (www.try-db.org/TryWeb/Home.php).

Finally (third objective), from those 100 selected studies (Supporting Information Appendix S1, Table S1.1), we also extracted rainfall partitioning data (mean values, standard deviations and sample size) for co-occurring native and invasive species in the same ecoregion (Olson et al., 2001) and described their geographic location in terms of aridity index in order to conduct a meta-analysis. We generated a second database with 25 studies (27 native and 19 invasive species) that met our requirements (i.e. co-occurring species), reaching 47,47 and 45 native-invasive species comparisons for interception, throughfall and stemflow, respectively (Supporting Information Appendix S2, Table S2.1). This database encompassed eight world regions (i.e. Africa, Asia, Australia, Central America, Europe, North America, Pacific Islands, South America; based on Richardson \& Rejmánek, 2011) and 12 ecoregions (i.e. Celtic broadleaf forests; Central Persian desert basins; Cerrado; Drakensberg montane grasslands, woodlands and forests; Dry Chaco; Eastern Australian temperate forests; Hawaii tropical dry forests; IsthmianAtlantic moist forests; Southeast Australia temperate forests; Southwest Iberian Mediterranean sclerophyllous and mixed forests; Tamaulipan matorral; and Valdivian temperate forests; based on Olson et al., 2001). Furthermore, for each native-invasive species comparison, we extracted the values of aridity of each location based on the geographic coordinates provided by the studies. The aridity index is a proxy of water availability and is calculated as the ratio of mean annual precipitation and potential evapotranspiration
(Trabucco \& Zomer, 2009). The geoprocessing was conducted using QGIS v.3.8.3 software (QGIS Development Team, 2014).

\subsection{Statistical analysis}

We conducted descriptive statistics in order to explore the rainfall partitioning into interception, throughfall and stemflow for all the invasive woody plant species included in the analysis ( $n=67$ species). Complementarily, we also described the rainfall partitioning for the 10 species with the widest invaded distribution range (see species details in Supporting Information Appendix S1, Tables S1.1 and S1.2). To analyse the influence of morphological attributes on rainfall partitioning fluxes (mean percentages per species), we performed different statistical analyses. Regardless of species identity, for categorical traits, we performed multiple one-way ANOVAs to test if the variation in fluxes is associated with species life-form (i.e. tree or shrubs), bark roughness (i.e. rough or smooth), leaf type (i.e. broadleaf, needle-leaf or pinnate-leaf), and leaf phenology (i.e. evergreen or deciduous). In cases where we found significant statistical differences among morphological attributes, we performed a Tukey's test. For quantitative traits, such as LAI, we used a generalized linear model fitted with a quasi-Poisson error distribution due to the over-dispersion found in the fitted model (Zuur et al., 2009).

We performed a principal coordinates analysis ( $P C O A)$ to characterize and identify groups of invasive species, according to their rainfall partitioning fluxes and morphological attributes. This multivariate technique is suitable for mixed data (i.e. continuous and categorical), and is performed on a dissimilarity matrix using Gower's distance (Gower, 1966). For this analysis, we used a subset of species for which we collected data for the three rainfall partitioning fluxes and all the plant morphological attributes $(n=53)$. To identify the main variables that explain the multivariate ordination we used the 'envfit' function with 1,000 permutations of the R package 'vegan' (Oksanen et al., 2019). This function assesses the goodness-of-fit of the analysis by calculating the squared correlation coefficient $\left(r^{2}\right)$ between the variables and any given multivariate ordination. The biplot resulting from the PCoA only shows significant correlation between the variables and multivariate ordination.

For comparing the rainfall partitioning between invasive and native species co-occurring in the same ecoregion, we carried out a meta-analysis. We used Hedges' $d$ as an estimate of the standardized mean difference (SMD) between invasive and native species to summarize the effect size of interception ( $n=47$ pairwise comparisons), throughfall ( $n=47)$ and stemflow $(n=45)$ on plant species groups. For each comparison, the SMD was calculated as: (M1 - M2)/sp; where M1 and M2 refer to the mean value of interception, throughfall and stemflow for invasive and native species, respectively, and $\mathrm{sp}$ is the pooled standard deviation of the two groups (Hedges \& Olkin, 1985). We fitted random-effects models to test the mean effect sizes of rainfall partitioning fluxes (interception, throughfall and stemflow) on species comparisons and mixed-effects models to test whether the mean effect sizes of these 
fluxes on species comparisons depend on a categorical moderator variable, using the 'escalc' and 'rma.mv' functions of the R package 'metafor' (Viechtbauer, 2010). The data set used in the meta-analysis presented two sources of nonindependence: multiple effect sizes had been taken (a) from each study and (b) from each species; therefore, both study and species were included as random factors (Nakagawa \& Santos, 2012). The mixed-effects models included the aridity index (Al) for each site as a categorical moderator variable (fixed factor). For this moderator, we grouped the values of $\mathrm{Al}$ in two classes: 'drylands' (Al < 0.65) and 'humid areas' (AI > 0.65) based on Trabucco and Zomer (2009) and Magliano, Whitworth-Hulse, and Baldi (2019). The effect sizes were considered significantly different from zero if their $95 \%$ confidence intervals $(\mathrm{Cl})$ did not include zero. Positive mean Hedges' $d$ effect sizes indicate that the invasive species have higher fluxes values than native species co-occurring in the same ecoregion, and vice versa. The heterogeneity of effect sizes (Q statistics; Hedges \& Olkin, 1985) and other details of model outputs are shown in Supporting Information Appendix S2, Tables S2.2-7. We explored the possibility of publication bias by performing the Kendall's rank correlation test and calculating the Rosenthal's fail safe number, which is considered robust if it is $>5 n+10$, where $n$ is the original number of studies (Rothstein et al., 2005). Kendall's rank correlation test was not significant for interception (Kendall's tau $=.15 ; p=.14$ ), indicating that there was no bias in the reporting of results from the studies included in this meta-analysis, but the tests were significant for throughfall (Kendall's tau $=-.24 ; p=.02$ ) and stemflow (Kendall's tau $=.43 ; p<.001$ ), suggesting publication bias. The observed Rosenthal's fail safe numbers were 39 for interception (expected value $>245$ ), 4,862 for throughfall (>245) and 12,465 for stemflow ( $>235$ ), indicating that results found are robust regardless of publication bias with the exceptions of the meta-analyses on interception (i.e. fail safe number lower than expected without publication bias). All the statistical analyses were performed using R v. 3.5.3 (R Core Team, 2017) and the following packages: mass, vegan, metafor, ggplot2, gridExtra. A $p$-value of .05 was used as a threshold for statistical significance.

\section{3 | RESULTS}

For the 67 invasive woody species included in the analysis, on average, interception accounted for $25 \%$ of total rainfall (ranging from 1.6-59.5\%), throughfall for $70.6 \%$ (39.1-92.7\%) and stemflow for $5.3 \%(0.1-31.6 \%)$ (Figure 1c). The top 10 species with a wide invaded distribution range had relatively high stemflow. On average, the values of interception, throughfall and stemflow were $22.9 \%$ (13-37.5\%), 68.1\% (56.1-86\%) and 12.4\% (0.7-31.6\%), respectively (Figure 1d; Supporting Information Appendix S1, Table S1.1).

Regarding the relationship between rainfall partitioning fluxes and morphological attributes, we did not find significant effects of life-form and leaf phenology on the fluxes (Table 1$)$. The relationships between LAl and interception ( $t=0.42 ; p=.68$ ), throughfall ( $t$ $=-0.08 ; p=.93)$ and stemflow $(t=0.21 ; p=.83)$ were also not statistically significant (see Supporting Information Appendix S1, Figure S1.1). Conversely, the bark roughness was the main morphological attribute influencing significantly both interception and stemflow, but not throughfall (Table 1). Interception mean values accounted for $20.3 \%$ of the total rainfall in species with smooth barks and $29.3 \%$ in those with rough barks, whereas the smooth-barked species had almost triple the percentage of stemflow of rough-barked species ( 8.7 and $3.2 \%$ of total rainfall, respectively). We also found that leaf type had an important role in regulating stemflow, but did not show an influence on interception or throughfall (Table 1). The broadleaf species showed higher stemflow than needle-leaf species (mean
TABLE 1 Mean values of interception, throughfall and stemflow (expressed as a percentage of total rainfall) and their relationship with morphological attributes of invasive woody plant species from a one-way ANOVA

\begin{tabular}{llccc} 
Morphological attributes & Interception (\%) & Throughfall (\%) & Stemflow (\%) \\
\hline Life-form & Tree & 25.5 & 70.8 & 5.3 \\
& Shrub & 27.1 & 65.7 & 4.9 \\
\cline { 2 - 4 } Bark roughness & F-statistic & - & 1.1 & 0.1 \\
& Smooth & 20.3 & 72.7 & 8.7 \\
& Rough & 29.3 & 68.8 & 3.2 \\
\hline \multirow{2}{*}{ Leaf type } & F-statistic & $6.9^{*}$ & 1.9 & $19.1^{* * *}$ \\
& Broadleaf & 21.5 & 72.1 & $6.8^{\mathrm{a}}$ \\
& Pinnate-leaf & 27.9 & 70.5 & $6.6^{\mathrm{ab}}$ \\
& Needle-leaf & 29.5 & 68.5 & $3.2^{\mathrm{b}}$ \\
& F-statistic & 2.5 & 1.0 & $3.2^{*}$ \\
\hline Leaf phenology & Deciduous & 26.1 & 70.9 & 5.4 \\
& Evergreen & 25.4 & 70.2 & 5.3 \\
& F-statistic & 0.0 & 0.1 & 0.0 \\
\hline
\end{tabular}

Note.: Different letters indicate significant differences for leaf type (Tukey's tests), while * and ${ }^{* * *}$ indicate $p<.05$ and $<.001$, respectively. Analysis of statistical differences in interception between trees and shrubs were not performed due to the insufficient shrub replicates. 
values of 6.8 and $3.2 \%$, respectively), whereas no significant differences were found comparing broadleaf species versus pinnate-leaf species, and pinnate-leaf species versus needle-leaf species.

The first two axes of the PCoA explained more than $67 \%$ of species variability according to their rainfall partitioning fluxes and morphological attributes (Figure 2). The species were significantly grouped according to two of the rainfall partitioning fluxes, interception $\left(r^{2}=.22 ; p<.01\right)$ and stemflow $\left(r^{2}=.29 ; p<.001\right)$. The species were also grouped according to their morphological characteristics such as bark roughness $\left(r^{2}=.92 ; p<.001\right)$, leaf type $\left(r^{2}=.38 ; p<.001\right)$ and leaf phenology $\left(r^{2}=.96 ; p<.001\right)$ (Figure 2). Throughfall, LAI and life-form did not significantly correlate with the multivariate ordination. At the positive end of the first PCoA axis (which accounted for $42.33 \%$ of the total variance), there was a group of species that had relatively high stemflow, low interception and smooth bark (Figure 2). Within this group, stemflow exceeded 15\% of the total rainfall (e.g. Acacia mearnsii, Ligustrum lucidum, Acacia holosericea, Ailanthus altissima), reaching a maximum of $31.6 \%$ in Psidium cattleianum. At the negative end, there was a group of rough-barked species with relatively low stemflow and high interception (Figure 2). Within this group, interception exceeded $40 \%$ of the total rainfall (e.g. Pinus halepensis, Schleichera oleosa, Kunzea ericoides), reaching a maximum of $62.3 \%$ in Pinus nigra. The second PCoA axis accounted for $24.85 \%$ of the total variance, and was mainly explained by leaf type and leaf phenology attributes. Along this axis, evergreen species with needle-leaf type (e.g. all species of the genus Pinus) and most broadleaf species (e.g. all species of the genus Eucalyptus) are found at the positive end (Figure 2), while deciduous species with both broadleaf (e.g.
Ailanthus altissima, Morus alba, Pyrus calleryana, Punica granatum) and pinnate-leaf type (e.g. most of Acacia spp.) were grouped at the negative end (Figure 2).

Regarding the comparison of rainfall partitioning between invasive and native species co-occurring in the same ecoregion, the mean effect size (Hedges' $d$; hereafter $d$ ) of interception (mean $d=0.20 ; 95 \% \mathrm{Cl}-0.26 / 0.67 ; z=0.86 ; p=.39$ ) and throughfall (mean $d=-1.12 ; 95 \% \mathrm{Cl}-2.99 / 0.76 ; z=-1.17 ; p=.24)$ did not differ significantly from zero, suggesting that these fluxes were similar between the two groups (Figure 3a; see Supporting Information Appendix S2, Table S2.2-7 for detailed model outputs). Conversely, the mean effect size $(d)$ of stemflow was positive and significantly larger than zero (mean $d=2.37 ; 95 \% \mathrm{Cl} 0.10 / 3.74 ; z=3.38 ; p<.001$ ), indicating that invasive species have higher stemflow than native species co-occurring in the same ecoregion (Figure 3a). Taking into account the aridity (i.e. categorical moderator variable) of the geographic location of the invasive-native species comparisons, we found that the mean effect size $(d)$ of interception did not depend on whether the species were located in drylands $(z=-1.243 ; p=.21)$ or humid areas $(z=1.79 ; p=.07$ ) (Figure $3 b)$. The mean effect size $(d)$ of throughfall was significantly larger than zero for drylands $(z=2.18 ; p=.03$ ) and humid areas $(z=-2.86 ; p=.004)$, but with opposite responses (Figure 3b). That is, the species comparisons were positive (i.e. higher throughfall for invasive than for native species) in drylands, while they were negative in humid areas (i.e. less throughfall for invasive than for native species). For species comparisons, mean effect size $(d)$ of stemflow was significantly larger than zero for drylands $(z=1.98 ; p=.047)$ and humid areas $(z=2.73 ; p=.006)$, showing

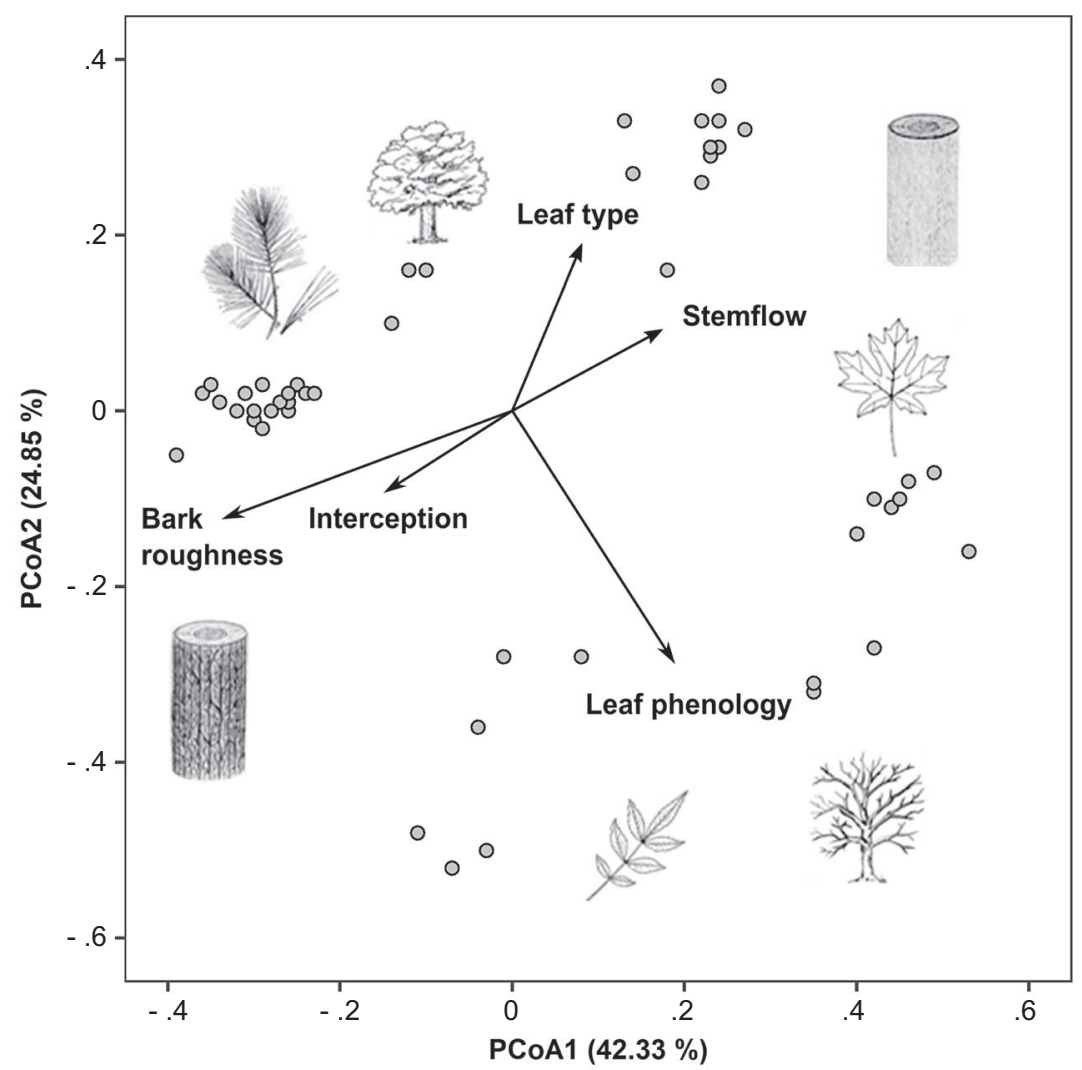

FIGURE 2 Biplot of principal coordinates analysis (PCoA) of invasive woody plant species $(n=53)$. The analysis included continuous variables related to rainfall partitioning (interception, throughfall and stemflow) and leaf area index (LAI), and categorical variables related to the morphological attributes of woody invasive species [bark roughness, leaf type, leaf phenology, life-form]. Each arrow shows the direction of the (increasing) gradient, and the length of each arrow is proportional to the squared correlation coefficient $\left(r^{2}\right)$ between the variable and the multivariate ordination. Throughfall, LAl and life-form did not significantly correlate with the multivariate ordination and, therefore, are not represented with arrows 
(a)

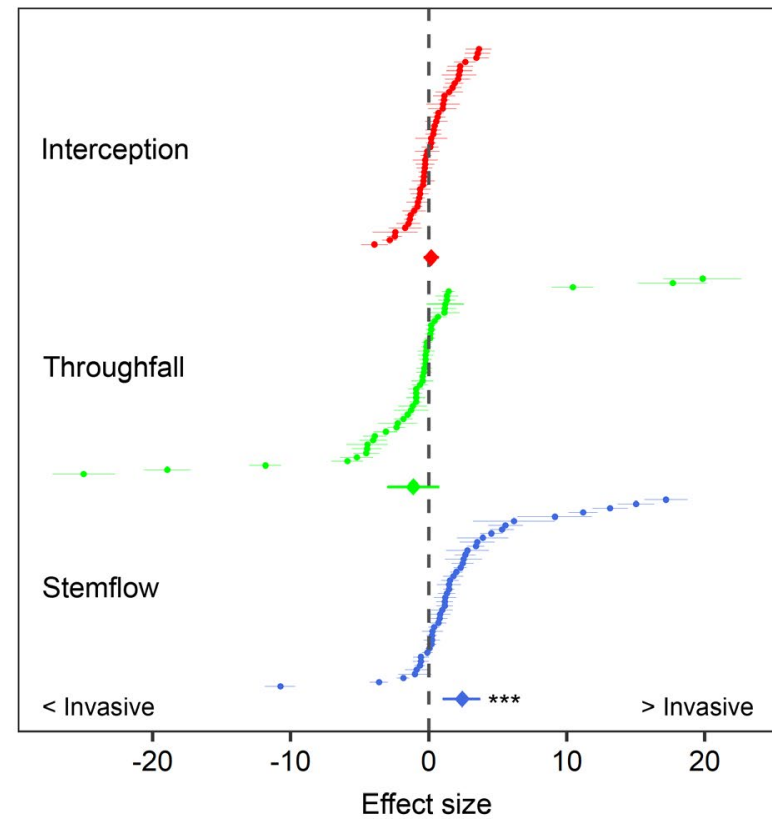

(b)



FIGURE 3 Comparison between native and invasive species co-occurring in the same ecoregion regarding their rainfall partitioning fluxes: interception ( $n=47$ pairwise comparisons), throughfall $(n=47)$ and stemflow $(n=45)$. (a) Mean effect sizes (Hedges' $d$ ) of rainfall partitioning fluxes on species pairs. Dots refer to the mean effect size for individual pairwise comparison, while diamonds represent the overall mean effect size estimate for each flux. (b) Mean effect sizes (Hedges' $d$ ) of each flux on species pairs including the aridity index (AI) class as a categorical moderator variable. Squares and triangles indicate the mean effect size for humid areas (Al values $>0.65$ ) and drylands (Al values $<0.65$ ), respectively ( $n$ humid areas $=34$ for three fluxes; $n$ drylands $=13,13,11$ for interception, throughfall and stemflow, respectively). The horizontal bars around the means refer to the $95 \%$ confidence intervals. Positive mean effect sizes indicate that the invasive species have higher flux values than native species co-occurring in the same ecoregion. A mean effect size is significantly different from zero when its $95 \%$ confidence interval does not include zero (significance levels $={ }^{*} p<.01 ;{ }^{* *} p<.001 ;{ }^{* * *} p<.0001$ )

positive responses (i.e. higher stemflow for invasive than for native species; Figure $3 b$ ). Given the variability observed for stemflow in drylands, we explored the distribution (native and invaded) range of those species that presented a greater importance of this flow (i.e. highest values). We found a small group of species that have notably invaded a wide range of water availability conditions, reaching areas drier than their native distribution range (Figure 4 and Supporting Information Appendix S1, Table S1.3). In particular, the invaded distribution ranges of Ailanthus altissima and Ligustrum lucidum (Figure 4c,d) not only exhibited a clear expansion of the aridity index extremes (see dots in Figure 4i,j), but also the median values moved towards areas drier than their native distribution ranges (see violin shapes in Figure 4i,j).

\section{4 | DISCUSSION}

To our knowledge, this is the first study that (a) reviews the rainfall partitioning by invasive woody plant species worldwide, (b) analyses how interception, throughfall and stemflow are related to multiple morphological characteristics of invasive species and (c) compares these fluxes between co-occurring invasive and native species. We found that bark roughness and leaf type are the most important attributes for determining the partitioning of rainfall. While roughbarked species constrain rainfall inputs by promoting higher interception losses, smooth-barked species with broad leaves enhance the amount of rainwater reaching the soil by maximizing stemflow. Pairwise comparisons showed that invasive species have higher stemflow values than native species for both drylands and humid areas, and higher throughfall in drylands, but less in humid areas. Hence, our results highlight that stemflow generation by invasive species might become an important ecohydrological process in invaded ecosystems.

As previously stated, the influence of bark roughness and leaf morphology on rainfall partitioning supports the findings of other regional and global studies focused on wild and cultivated plant species (Llorens \& Domingo, 2007; Magliano, Whitworth-Hulse, \& Baldi, 2019; Van Stan et al., 2020). Conversely, we did not find an important role in rainfall partitioning of leaf phenology, life-form and leaf area index as many studies did (Magliano, Whitworth-Hulse, Florio, et al., 2019; Park \& Cameron, 2008). In our study, we observed that the interception mean value is 1.4 times lower in smooth-barked species in comparison with rough-barked species, while the stemflow mean value is 1.7 times higher in species with smooth barks. These variations in interception and stemflow have been mainly attributed to differences in plant water storage capacity (Takahashi 


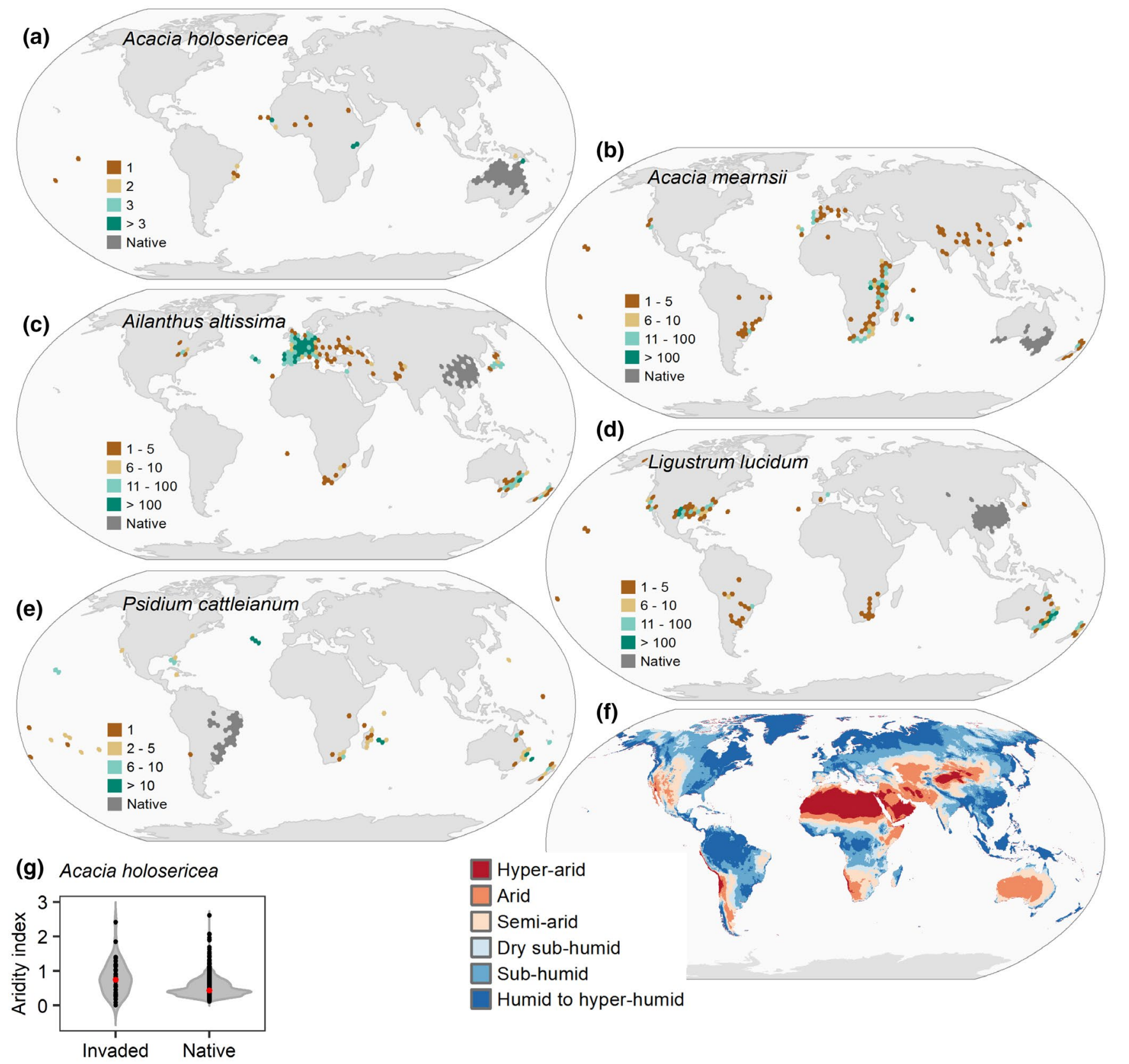

(h) Acacia mearnsii

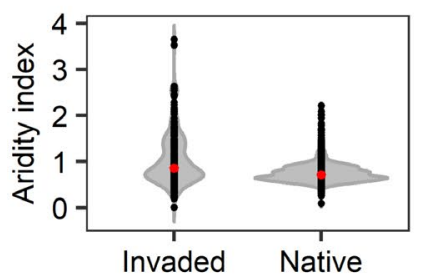

(i) Ailanthus altissima

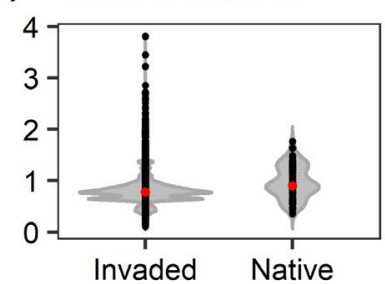

(j) Ligustrum lucidum



(k) Psidium cattleianum

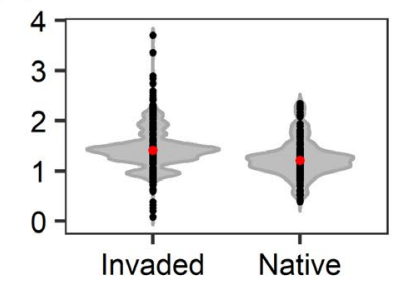

FIGURE 4 The invaded and native distribution range of the five species with the highest stemflow values: Acacia holosericea (a), Acacia mearnsii (b), Ailanthus altissima (c), Ligustrum lucidum (d) and Psidium cattleianum (e); and (f) the global distribution of the aridity index (ratio of mean annual precipitation and potential evapotranspiration). Numbers indicate the amount of species occurrence coordinates within a regular hexagonal grid (with a cell side of 1.6 degrees). Violin plots of the aridity index of the occurrence coordinates (black dots) within the invaded and native distribution range of Acacia holosericea $(\mathrm{g})(n=48$ invasive occurrence coordinates; $n=2,660$ native occurrence coordinates), Acacia mearnsii (h) ( $n=1,731 ; 14,048)$, Ailanthus altissima (i) ( $n=18,895 ; 195)$, Ligustrum lucidum (j) $(n=4,117 ; 625)$ and Psidium cattleianum $(k)(n=1,825 ; 449)$. The width of each violin reflects the density of occurrence coordinates and the central red dot represents the median value 
et al., 2011), but also to the branch inclination and the presence of epiphytes (Carlyle-Moses \& Gash, 2011). Furthermore, broadleaf species present higher stemflow (2.1 times) than needle-leaved species, which are almost all rough-barked coniferous, suggesting a better 'funnelling capacity' for the first ones, favoured by differences in leaf area (Barbier et al., 2009; Spencer \& van Meerveld, 2016). Therefore, morphological attributes of species regulate rainfall partitioning and thus the amount of water reaching the soil, which highlights at least two consequences for the invasive species and the invaded ecosystems: (a) the hydrological advantage of stemflow (i.e. a localized rainwater input) for invasive species that maximize this flux, particularly in water-limited ecosystems, and the (b) hydrological impacts of invasive plants in the context of climate change.

Overall, the results of our pairwise comparisons suggest that throughfall and particularly stemflow might represent essential inputs of water for invasive species, which could contribute to enhancing plant growth in invaded environments (Sadeghi et al., 2017). Localized rainwater inputs infiltrating into the soil profile next to the root zone represents a hydrological advantage for those invasive species capable of consuming this flow in water-limited environments (Levia \& Germer, 2015; Van Stan et al., 2020). For example, the species with the highest inputs due to stemflow are all smooth-barked plants and have invaded drier areas than their native distribution range (i.e. Ailanthus altissima, Ligustrum lucidum, Psidium cattleianum, Acacia mearnsii and Acacia holosericea; see Figure 4 and Supporting Information Appendix S1, Text S1.1, Table S1.3). Therefore, the increase in water inputs via stemflow may contribute to improving these species performance in stressful environments. In particular, Ligustrum lucidum is from humid and sub-humid ecoregions of eastern China (Dreyer et al., 2019; Montti et al., 2016), but the species successfully invades drylands such as the mountain dry forests of Dry Chaco in central Argentina (Fernandez et al., 2020). There, the invader shows higher rainwater input in comparison with the dominant native species (Whitworth-Hulse et al., 2020). Furthermore, a relatively high stemflow for invasive species can provide several competitive advantages over native vegetation. First, by reducing the rainwater that reaches the ground via throughfall (see Figure 1a) and, therefore, reducing the water availability for the understorey vegetation (i.e. competitors). Second, by collecting nutrients along the trip from the canopy to the ground, increasing nutrient inputs and enhancing plant nutrient recycling (Levia \& Germer, 2015; Van Stan et al., 2020). Finally, - for some species - by distributing allelopathic compounds into the soil layers affecting native species performance (e.g. Ailanthus altissima; Sadeghi et al., 2017). Hence, rainfall partitioning, and specifically the generation of stemflow might have a key ecological role in the invaded ecosystems.

The ecohydrological changes associated with woody plant invasions might become increasingly important in the context of global climate change. The expected increase of the intensity and event size of precipitation in some regions will increase the volume of water dripping from the canopy and stemflow (Van Stan et al., 2020). Huang et al., (2016) project that drylands will increase their area by $11-23 \%$ relative to a $1961-1990$ baseline, reaching more than $50 \%$ of total land surface by the end of this century. Therefore, as previously stated, relatively high throughfall and stemflow for invasive species could be advantageous in these areas since it might allow species to cope with the stressful conditions through a higher water input. Conversely, morphological characteristics that reduce water inputs through higher interception and/or lower stemflow (i.e. species with rough barks and needle leaves) might have negative consequences for local hydrological processes and nutrient cycling (Carlyle-Moses \& Gash, 2011; Vilà \& Hulme, 2017). Although we did not find a significant mean effect size of interception on invasive-native species pairs either for humid areas or drylands, our analysis includes a group of cultivated species with relatively high interception losses. The expansion of species with these characteristics might determine a scenario of less soil water availability (Little et al., 2009; Sadeghi et al., 2016). Many conifers and other cultivated species become invasive and expand their distribution range from the area occupied by the commercial plantations, causing negative impacts on ecosystems (Nuñez et al., 2017; Richardson \& Rejmánek, 2004). For instance, commercial plantations of species included in our study, such as Pinus nigra, Pinus halepensis and Schleichera oleosa, intercept approximately $50 \%$ of total rainfall inputs (Supporting Information Appendix S1, Table S1.1), reducing soil water content. Among invaded regions with marked water limitations, the best example that combines the hydrological effects of annual plant transpiration and rainwater loss via canopy interception is South Africa, where a reduction of $7 \%$ in surface water runoff due to woody species invasion has been documented (i.e. Acacia spp., Eucalyptus spp., Hakea spp., Pinus spp., Populus spp.; van Wilgen et al., 2008). In summary, less rainwater reaching the soil, together with high water consumption of invasive plants, might generate a reduction of water availability for recharging groundwater and also streamflow (Farley et al., 2005; Le Maitre et al., 2015; Takahashi et al., 2011). These results will become increasingly important for the maintenance or increase of human well-being, highlighting the need for further inquiries determining the ecohydrological impacts on water provision of woody invasive species at the catchment scale.

\section{5 | CAVEATS, LIMITATIONS, AND A WAY FORWARD}

Our literature review suggests that the frameworks focused on rainfall partitioning by exotic species in the context of invasion ecology are extremely scarce, reinforcing the need to increase studies on this topic. Our database includes many species used for commercial plantation and ornamental purposes (Supporting Information Appendix S1, Table S1.1), so information on rainfall partitioning, together with known transpiration values of invasive plants (Cavaleri \& Sack 2010; Vilà \& Hume, 2017), may be useful for many purposes and sectors, such as the forestry industry, afforestation and restoration planning, ornamental plant designs in urban areas and also for governmental policies in terms of water resource management (Farley et al., 2005; Le Maitre et al., 2015; Sadeghi et al., 2016). 
Although our study has not addressed how interception, throughfall and stemflow may be involved in the invasion process, it might guide further multi-approach studies that analyse possible links between these fluxes and woody plant invasiveness (Pyšek \& Richardson, 2008). For example, experimental approaches that evaluate woody plant transpiration, growth and reproduction by manipulating stemflow generation across a water availability gradient would be valuable. These experiments will allow us to test if the invasive species that have high stemflow generation also have higher performance due to their capacity to access to more water. Furthermore, studies combining different disciplines (e.g. invasion ecology, ecohydrology), methodological approaches (e.g. experiments, simulations), spatial levels (e.g. local, regional, global), and organizational levels (i.e. population, community, ecosystem) will be crucial for a better understanding of the ecological role of rainfall partitioning by invasive species.

\section{6 | CONCLUSION}

This study synthesizes the global patterns of how rainfall is partitioned into interception, throughfall and stemflow for invasive species and its ecohydrological implications. More rainwater reaches the topsoil under invasive species in comparison with cooccurring native species in water-limited environments. Therefore, specific morphological attributes such as smooth barks and broad leaves that maximize water inputs may represent an ecological advantage for invasive plants. Conversely, from an ecosystem perspective, the invasion of cultivated species with rough barks and needle leaves and relatively high interception could have a negative impact on the local water balance (i.e. less soil water availability). Overall, these insights suggest that the ecological role of stemflow, throughfall and interception should be considered in future plant invasions research, particularly in the context of climate change, biodiversity loss, and the urgent need to restore many ecosystems.

\section{ACKNOWLEDGMENTS}

We would like to thank Mr. Charles Whitworth-Hulse and the Gabinete de Asesoramiento en Escritura Científica en Inglés (GAECl - Universidad Nacional de San Luis) for critical reading of the manuscript. This work was funded by a grant from the Agencia Nacional de Promoción Científica y Tecnológica - Argentina (PICT 2016-4136).

\section{AUTHOR CONTRIBUTIONS}

The authors confirm contribution to the paper as follows: study conception and design: Juan I. Whitworth-Hulse; data collection: Juan I. Whitworth-Hulse and Patricio N. Magliano; analysis and interpretation of results: Juan I. Whitworth-Hulse and Sebastián R. Zeballos; draft manuscript preparation: Juan I. Whitworth-Hulse, Sebastián Aguiar, Germán Baldi and Sebastián R. Zeballos. All authors reviewed the results and approved the final version of the manuscript.

\section{DATA AVAILABILITY STATEMENT}

Data available from the Dryad Digital Repository: https://doi. org/10.5061/dryad.dfn2z34zv. Data are fully public but should be appropriately referenced by citing this data paper.

\section{ORCID}

Juan I. Whitworth-Hulse (iD https://orcid.

org/0000-0001-6454-5227

\section{REFERENCES}

Barbier, S., Balandier, P., \& Gosselin, F. (2009). Influence of several tree traits on rainfall partitioning in temperate and boreal forests: A review. Annals of Forest Science, 66, 1-11. https://doi.org/10.1051/ forest/2009041

Carlyle-Moses, D. E., \& Gash, J. H. (2011). Rainfall interception loss by forest canopies. In D. F. Levia, D. E. Carlyle-Moses, \& T. Tadashi (Eds.), Forest hydrology and biogeochemistry (pp. 407-423). Springer. https://doi.org/10.1007/978-94-007-1363-5_20

Cavaleri, M. A., \& Sack, L. (2010). Comparative water use of native and invasive plants at multiple scales: A global meta-analysis. Ecology, 91, 2705-2715. https://doi.org/10.1890/09-0582.1

Coenders-Gerrits, M., Schilperoort, B., \& Jiménez-Rodríguez, C. (2020). Evaporative processes on vegetation: An inside look. In J. T. Van Stan, E. Gutmann, \& J. Friesen (Eds.), Precipitation partitioning by vegetation (pp. 35-48). Springer. https://doi.org/10.1007/978-3-030-297022_3

Dreyer, J. B. B., Higuchi, P., \& Silva, A. C. (2019). Ligustrum lucidum WT Aiton (broad-leaf privet) demonstrates climatic niche shifts during global-scale invasion. Scientific Reports, 9, 3813. https://doi. org/10.1038/s41598-019-40531-8

Ehrenfeld, J. G. (2010). Ecosystem consequences of biological invasions. Annual Review of Ecology, Evolution, and Systematics, 41, 59-80. https://doi.org/10.1146/annurev-ecolsys-102209-144650

Farley, K. A., Jobbágy, E. G., \& Jackson, R. B. (2005). Effects of afforestation on water yield: A global synthesis with implications for policy. Global Change Biology, 11, 1565-1576. https://doi. org/10.1111/j.1365-2486.2005.01011.x

Fernandez, R. D., Ceballos, S. J., Aragón, R., Malizia, M., Montti, L., Whitworth-Hulse, J. I., Castro-Díez, P., \& Grau, R. A. (2020). A global review of Ligustrum lucidum (OLEACEAE) invasion. The Botanical Review, 86(2), 1-26. https://doi.org/10.1007/s12229-020-09228-w

Gower, J. C. (1966). Some distance properties of latent root and vector methods used in multivariate analysis. Biometrika, 53, 325-338. https://doi.org/10.1093/biomet/53.3-4.325

Gross, N., Börger, L., Duncan, R. P., \& Hulme, P. E. (2013). Functional differences between alien and native species: Do biotic interactions determine the functional structure of highly invaded grasslands? Functional Ecology, 27, 1262-1272. https://doi.org/10.1111/ 1365-2435.12120

Hedges, L. V., \& Olkin, I. (1985). Statistical methods for meta-analysis, : Academic Press.

Huang, J., Yu, H., Guan, X., Wang, G., \& Guo, R. (2016). Accelerated dryland expansion under climate change. Nature Climate Change, 6(2), 166-171. https://doi.org/10.1038/nclimate2837

Le Maitre, D. C., Gush, M. B., \& Dzikiti, S. (2015). Impacts of invading alien plant species on water flows at stand and catchment scales. AoB Plants, 7, https://doi.org/10.1093/aobpla/plv043

Levia, D. F., \& Germer, S. (2015). A review of stemflow generation dynamics and stemflow-environment interactions in forests and shrublands. Reviews of Geophysics, 53, 673-714. https://doi.org/10.1002/2015R G000479

Li, X. Y., Liu, L. Y., Gao, S. Y., Ma, Y. J., \& Yang, Z. P. (2008). Stemflow in three shrubs and its effect on soil water enhancement in semiarid 
loess region of China. Agricultural and Forest Meteorology, 148(10), 1501-1507. https://doi.org/10.1016/j.agrformet.2008.05.003

Little, C., Lara, A., McPhee, J., \& Urrutia, R. (2009). Revealing the impact of forest exotic plantations on water yield in large scale watersheds in South-Central Chile. Journal of Hydrology, 374, 162-170. https:// doi.org/10.1016/j.jhydrol.2009.06.011

Llorens, P., \& Domingo, F. (2007). Rainfall partitioning by vegetation under Mediterranean conditions. A review of studies in Europe. Journal of Hydrology, 335, 37-54. https://doi.org/10.1016/j.jhydr ol.2006.10.032

Magliano, P. N., Whitworth-Hulse, J. I., \& Baldi, G. (2019). Interception, throughfall and stemflow partition in drylands: Global synthesis and meta-analysis. Journal of Hydrology, 568, 638-645. https://doi. org/10.1016/j.jhydrol.2018.10.042

Magliano, P. N., Whitworth-Hulse, J. I., Florio, E. L., Aguirre, E. C., \& Blanco, L. J. (2019). Interception loss, throughfall and stemflow by Larrea divaricata: The role of rainfall characteristics and plant morphological attributes. Ecological Research, 34(6), 753-764. https:// doi.org/10.1111/1440-1703.12036

Montti, L., Ayup, M. M., Aragón, R., Qi, W., Ruan, H., Fernández, R., Casertano, S. A., \& Zou, X. (2016). Herbivory and the success of Ligustrum lucidum: Evidence from a comparison between native and novel ranges. Australian Journal of Botany, 64, 181-192. https://doi. org/10.1071/BT15232

Nakagawa, S., \& Santos, E. S. (2012). Methodological issues and advances in biological meta-analysis. Evolutionary Ecology, 26(5), 1253-1274. https://doi.org/10.1007/s10682-012-9555-5

Nuñez, M. A., Chiuffo, M. C., Torres, A., Paul, T., Dimarco, R. D., Raal, P., Policelli, N., Moyano, J., García, R. A., van Wilgen, B. W., Pauchard, A., \& Richardson, D. M. (2017). Ecology and management of invasive Pinaceae around the world: Progress and challenges. Biological Invasions, 19, 3099-3120. https://doi.org/10.1007/s1053 0-017-1483-4

Nunez-Mir, G. C., Guo, Q., Rejmánek, M., Iannone, B. V. III., \& Fei, S. (2019). Predicting invasiveness of exotic woody species using a traits-based framework. Ecology, 100(10), e02797. https://doi. org/10.1002/ecy.2797

Oksanen, J., Blanchet, F. G., Friendly, M., Kindt, R., Legendre, P., McGlinn, D., Minchin, P. R., O'Hara, R. B., Simpson, G. L., Solymos, P., Stevens, M. H. H., Szoecs, E., \& Wagner, H. (2019). vegan: Community Ecology Package. $R$ package version 2.5-6. Retrieved from https://CRAN.Rproject.org/package=vegan

Olson, D. M., Dinerstein, E., Wikramanayake, E. D., Burgess, N. D., Powell, G. V. N., Underwood, E. C., D'amico, J. A., Itoua, I., Strand, H. E., Morrison, J. C., Loucks, C. J., Allnutt, T. F., Ricketts, T. H., Kura, Y., Lamoreux, J. F., Wettengel, W. W., Hedao, P., \& Kassem, K. R. (2001). Terrestrial ecoregions of the world: A new map of life on earth. BioScience, 51(11), 933. https://doi. org/0.1641/0006-3568(2001)051[0933:TEOTWA]2.0.CO;2

Park, A., \& Cameron, J. L. (2008). The influence of canopy traits on throughfall and stemflow in five tropical trees growing in a Panamanian plantation. Forest Ecology and Management, 255, 19151925. https://doi.org/10.1016/j.foreco.2007.12.025

Pyšek, P., \& Richardson, D. M. (2008). Traits associated with invasiveness in alien plants: Where do we stand? In W. Nentwig (Eds.), Biological invasions (pp. 97-125). Springer. https://doi.org/10.1007/978-3-54036920-2_7

QGIS Development Team (2014). QGIS geographic information system. Open Source Geospatial Foundation Project. http://www.qgis.org/ en/site/

R Core Team (2017). R: A language and environment for statistical computing. R Foundation for Statistical Computing. Retrieved from https:// cran.r-project.org/
Rejmánek, M., \& Richardson, D. M. (2013). Trees and shrubs as invasive alien species-2013 update of the global database. Diversity and Distributions, 19, 1093-1094. https://doi.org/10.1111/ddi.12075

Richardson, D. M., \& Rejmánek, M. (2004). Conifers as invasive aliens: A global survey and predictive framework. Diversity and Distributions, 10, 321-331. https://doi.org/10.1111/j.1366-9516.2004.00096.x

Richardson, D. M., \& Rejmánek, M. (2011). Trees and shrubs as invasive alien species-A global review. Diversity and Distributions, 17, 788809. https://doi.org/10.1111/j.1472-4642.2011.00782.x

Rothstein, H. R., Sutton, A. J., \& Borenstein, M. (2005). Publication bias in meta-analysis. John Wiley \& Sons.

Sadeghi, S. M. M., Attarod, P., Van Stan, J. T., \& Pypker, T. G. (2016). The importance of considering rainfall partitioning in afforestation initiatives in semiarid climates: A comparison of common planted tree species in Tehran, Iran. Science of the Total Environment, 568, 845-855. https://doi.org/10.1016/j.scitotenv.2016.06.048

Sadeghi, S. M. M., Gordon, D. A., \& Van Stan, J.T., II. (2020). A global synthesis of throughfall and stemflow hydrometeorology. In J. T. Van Stan, E. Gutmann, \& J. Friesen (Eds.), Precipitation partitioning by vegetation (pp. 49-70). Springer. https://doi.org/10.1007/978-3030-29702-2_4

Sadeghi, S. M. M., Van Stan, J. T., Pypker, T. G., \& Friesen, J. (2017). Canopy hydrometeorological dynamics across a chronosequence of a globally invasive species, Ailanthus altissima (Mill., tree of heaven). Agricultural and Forest Meteorology, 240, 10-17. https://doi. org/10.1016/j.agrformet.2017.03.017

Safeeq, M., \& Fares, A. (2014). Interception losses in three non-native Hawaiian forest stands. Hydrological Processes, 28, 237-254. https:// doi.org/10.1002/hyp.9557

Spencer, S. A., \& van Meerveld, H. J. (2016). Double funnelling in a mature coastal British Columbia forest: Spatial patterns of stemflow after infiltration. Hydrological Processes, 30(22), 4185-4201. https:// doi.org/10.1002/hyp.10936

Takahashi, M., Giambelluca, T. W., Mudd, R. G., DeLay, J. K., Nullet, M. A., \& Asner, G. P. (2011). Rainfall partitioning and cloud water interception in native forest and invaded forest in Hawai'i Volcanoes National Park. Hydrological Processes, 25, 448-464. https://doi.org/10.1002/ hyp.7797

Trabucco, A., \& Zomer, R. J. (2009). Global aridity index (global-aridity) and global potential evapo-transpiration (global-PET) geospatial database. CGIAR Consortium for Spatial Information. Retrieved from https:// cgiarcsi.community/data/global-aridity-and-pet-database/

Van Kleunen, M., Weber, E., \& Fischer, M. (2010). A meta-analysis of trait differences between invasive and non-invasive plant species. Ecology Letters, 13, 235-245. https://doi. org/10.1111/j.1461-0248.2009.01418.x

Van Stan, J.T., II., Gutmann, E., \& Friesen, J. (2020). Precipitation partitioning by vegetation: A global synthesis. Springer Nature.

van Wilgen, B. W., Reyers, B., Le Maitre, D., Richardson, D., \& Schonegevel, L. (2008). A biome-scale assessment of the impact of invasive alien plants on ecosystem services in South Africa. Journal of Environmental Management, 89, 336-349. https://doi.org/10.1016/j. jenvman.2007.06.015

Viechtbauer, W. (2010). Conducting meta-analyses in R with the metafor package. Journal of Statistical Software, 36(3), 1-48.

Vilà, M., \& Hulme, P. E. (2017). Impact of biological invasions on ecosystem services. Springer.

Whitworth-Hulse, J. I., Magliano, P. N., Zeballos, S. R., Gurvich, D. E., Spalazzi, F., \& Kowaljow, E. (2020). Advantages of rainfall partitioning by the global invader Ligustrum lucidum over the dominant native Lithraea molleoides in a dry forest. Agricultural and Forest Meteorology, 290(108013), https://doi.org/10.1016/j.agrfo rmet.2020.108013 
Zuur, A., leno, E. N., Walker, N., Saveliev, A. A., \& Smith, G. M. (2009) Mixed effects models and extensions in ecology with $R$. Springer Science $\&$ Business Media.

\section{BIOSKETCH}

From the beginning, Juan I. Whitworth-Hulse's scientific interest was in the area of biological invasions. He has worked on assessing the effects of woody plants invasion on hydrological processes in drylands. Currently, his research is focused on the ecohydrology changes of flat sedimentary landscapes and their association with native vegetation replacement by agriculture.

\section{SUPPORTING INFORMATION}

Additional supporting information may be found online in the Supporting Information section.

How to cite this article: Whitworth-Hulse JI, Magliano PN, Zeballos SR, Aguiar S, Baldi G. Global patterns of rainfall partitioning by invasive woody plants. Global Ecol Biogeogr. 2020;00:1-12. https://doi.org/10.1111/geb.13218 